\title{
A Conceptual Exploration of the Human Development Paradigm
}

\author{
Patrick A. Edewor, Ph.D \\ Department of Sociology, Covenant University, \\ P. M. B. 1023, Ota, Ogun State, Nigeria \\ Email: patrick.edewor@covenantuniversity.edu.ng, edeworpat@yahoo.com
}

\section{Doi:10.5901/mjss.2014.v5n6p381}

\begin{abstract}
In spite of the fact that the idea of development has been a central feature of human thought for millennia, the concept of development is still being improved upon owing to its complexity. Prior to the 1990s, the concept was poorly conceived and narrowly defined in terms of economic growth or increasing income using GNP as the yardstick for measuring the progress of nations. This approach was not a very good way of thinking about development because it was not concerned with advancing human well-being and human freedom. Human development came as an alternative development paradigm. This paper explores the emergence, meaning and aspects of human development as a development paradigm as well as its measurement with reference to the Human Development Index and its various modifications. The concepts of capabilities and freedom are discussed and the paper concludes that education or being knowledgeable and skill acquisition constitute the foundations for building all other capabilities by which human choices are enlarged and human well-being, enhanced.
\end{abstract}

Keywords: Development, human development, well-being, capabilities, freedom, choices.

\section{Introduction}

The idea of development has been a central feature of human thought for millennia and it has spanned different civilizations and vastly different cultural traditions. However, the way development is defined is still thought to be something that could be improved upon. This is essentially because the idea of development is a complex one. When the subject began in the 1940s, it was primarily driven by the progress in economic growth theory that had occurred through the preceding period in the 1930s as well as the 1940s. Development as was pursued in the last sixty years, particularly before the last decade of the 20th century, was poorly conceived and narrowly defined. It was dominated by the basic vision that poor countries are just low-income countries, and the focus was simply on transcending the problems of underdevelopment through economic growth, increasing GNP, etc. That idea proved to be a not very good way of thinking about development, for development has to be concerned with advancing human well-being and human freedom. Although income is one of the factors that contribute to welfare and freedom, it is not the only factor. While income and economic growth are not irrelevant, they constitute a rather poor basis for judging the progress of a country; the process of economic growth is just one among many factors.

Going back in history to the time of Adam Smith, John Stuart Mill, Karl Marx, to mention but a few, it will be observed that the development agenda, right from the beginning, had a concern with human life. Philosophers, economists and political leaders have long emphasized human well-being as the purpose, the end, of development. Reference to and emphases on "human good", "flourishing lives" and human beings as the "real end" of all activities were made and are found in the writings of various philosophers from Aristotle to Emmanuel Kant and among the leading political economists from Adam Smith to David Ricardo, Thomas Malthus, Karl Marx and John Stuart Mill (Jiyad, 1998). That was why Aristotle, in ancient Greece, asserted that: "Wealth is evidently not the good we are seeking, for it is merely useful for the sake of something else." Human development, as an approach, is concerned with what Amartya Sen considers to be the basic development idea, which is: advancing the richness of human life, rather than the richness of the economy in which human beings live. Advancing the richness of the economy is only a part and not what development entirely is.

This paper presents an exploration of the human development paradigm. It begins by discussing the origin or emergence of the paradigm and then proceeds to do a comprehensive clarification of the concept. There after, it presents the aspects of human development and then a description of its measurement. This is followed by an examination of Amartya Sen's capabilities approach with particular reference to the most basic capabilities and then argues that human capabilities can primarily be built through being educated, becoming knowledgeable and through relevant skill acquisition 
as these constitute the foundation for the building of all other capabilities. The section on capabilities is then followed by a conclusion.

\section{Emergence of the Human Development Paradigm}

For decades prior to 1990, Gross National Product (GNP) remained the singular instrument used by economists to measure the progress of nations. It was the measure of the total value of goods and services produced in a country. This measure, however, had a number of shortcomings. For example, it was unable to give information on the quality of life of the people, for instance, letting us know about the health of children, the quality of education, etc. It focused on economic growth - with or without equity considerations. Economic development was conceptualized as "a process whereby real per capita income of a country increases over a long period of time while simultaneously poverty reduced and inequality in society is generally diminished - or at least not increased" (Martinussen, 1996).

This was the kind of conception that was adopted by the World Bank in its analyses and which also informed its strategies since early 1970s. Considerable fluctuations were, however, observed in the World Bank's strategies up till around 1980. The World Bank was mainly interested in combining growth in per capita income with special assistance to the poor. The different strategies came under different names. For example, there was at one time a strategy described as "distribution with growth", while at another time there was the "basic needs strategy". The focus shifted to aggregate growth in conjunction with restoration of macro-economic balances, structural adjustment, and increased foreign exchange earnings in the 1980s. Yet, in the 1990s the Bank's emphasis was on growth for the poor and resource-weak groups - along with aggregate growth - in its overall conception of development (World Bank, 1980; 1990; Martinussen, 1996). Embodied in this conception of economic development was the desire, in principle, to improve the living conditions and welfare of the members of society. However, indicators and measures remained limited to income and growth in real incomes remained the target. Apart from the fact that there are major limits or drawbacks in the use of GNP in assessing the status of development in various countries (Haque, 2004), there are also considerable economic, political, and cultural implications in using GNP as an indicator of development or of enhancing GNP as a primary national goal.

Some prominent economists such as Amartya Sen, Paul Streeten, Mahbub ul Haq and some others criticized this idea of development. They argued that increased incomes should be a means to improve human welfare, not an end in itself (Sen, 1988; Streeten, 1994). They considered human welfare as overall objective of development. They were also of the view that even though increased incomes measured in terms of GNP per capita and national economic growth were essential for improvement in living conditions, they were not the only preconditions. In many countries, such economic growth was not reflected in or did not result to improved education or improved health standards translated into higher life expectancy.

Owing to the shortcomings of GNP as a measure of development, the concept of human development emerged as an alternative development paradigm as against definitions of development which focused on economic growth (Martinussen, 1996; Engler, 2005). This new view of development began percolating in the global South close to the end of the 1960s, precisely in 1968. In the next two decades, this new paradigm came to present a serious challenge to the hitherto existing economic growth school obsessed solely with GNP as a measure of development (Engler, 2005).

Under the leadership of the Pakistani economist, Mahbub ul Haq, the first United Nation's Development Programme (UNDP) Human Development Report was prepared which appeared on the international stage in 1990. The new human development paradigm was clearly presented in that first Human Development Report and it was tirelessly cultivated by Haq until his death in 1998. As argued in that first report,

while growth in national production ... is absolutely necessary to meet essential human objectives, what is important is to study how this growth translates - or fails to translate - into human development in various societies (UNDP, 1990).

In other words, what is of interest is the actual welfare or well-being of the citizens of a country. The report further argues that:

the purpose of development is to offer people more options. One of the options is access to income - not as an end itself but as a means to acquiring human well-being. But there are other options as well, including long life, knowledge, political freedom, personal security, community participation and guaranteed human rights (UNDP, 1990).

For over two decades, this brand of development thinking has been propagated by UNDP through the annual Human Development Reports. It differs sharply from the Washington Consensus, a phrase often seen as synonymous with neo-liberalism but which was first presented in 1989 by John Williamson to describe a set of policies believed to be 
the formula for promoting economic growth in Latin America (Williamson, 1990). Though this view of development is not framed as a radical enterprise, it has armed advocates of global justice with statistics that cut through the rhetoric of neoliberal triumphalism. It has challenged the dominance of GNP or economic growth as a measure of well-being, placing the condition of the world's poor at the centre of international dialogue.

\title{
3. The Concept of Human Development
}

The concept of human development has been variously defined. In developmental biology, human development is seen as "the physical and mental process of growing from one-celled zygote to an adult human being." ${ }^{1}$ The term "human development" is also used to refer to "developmental psychology" which is the scientific study of progressive psychological changes that occur in human beings as they age. Developmental psychology was originally concerned with infants and children. Later on, other periods of great change such as adolescence and aging became part of its concern. As a field of study, it now encompasses the entire life span and it examines change across a broad range of topics including motor skills and other psychological processes, problem solving abilities, conceptual understanding, acquisition of language, moral understanding, and identity formation. ${ }^{2}$

Closely related to the above definitions are two conceptions as discussed by Lerner (1998). One, most often seen in the early history of growth-oriented child development, defines human development as "the unfolding of the characteristics and capacities as one ages." The other, often used in developmental psychology, sees human development as "the patterns of skills, attitudes and behaviours that emerge over the life course." These two definitions are not discordant; their distinguishing factor rests in their assumptions and theoretical underpinnings. Yet another definition is that given by Freeman (1984, cited in Obayan, 2005) which sees human development as "the ability to exercise increasing control over one's life, being self reliant, fulfilling personal potential and accepting responsibility for one's action."

The above biological and psychological conceptions of human development are not the primary concern of this paper. Rather, we are interested in the concept of human development in the context propounded by United Nations Development Programme (UNDP) under the leadership of Mahbub ul Haq, as contained in the first Human Development Report (HDR) released in 1990. According to that report, human development is:

\begin{abstract}
A complex concept of development, based on the priority of human well-being, and aimed at ensuring and enlarging human choices which lead to equality of opportunities for all people in society and empowerment of people so that they participate in - and benefit from - the development process. ${ }^{3}$
\end{abstract}

The concept was intended to be an alternative development paradigm - an alternative to the hitherto existing conception of development which placed premium on Gross National Product (GNP) or economic growth and increase in real incomes. The argument, as aptly put by Mahbub ul Haq is as follows:

The basic purpose of development is to enlarge people's choices. In principle, these choices can be infinite and can change over time. People often value achievements that do not show up at all, or not immediately, in income or growth figures: greater access to knowledge, better nutrition and health services, more secure livelihoods, security against crime and physical violence, satisfying leisure hours, political and cultural freedoms and sense of participation in community activities. The objective of development is to create an enabling environment for people to enjoy long and healthy lives. ${ }^{4}$

It can be seen from the above that human development goes beyond the rise or fall of national incomes. It is a holistic development model that embraces every development issue, ranging from economic growth to social investment, people's empowerment, provision of basic needs, as well as political and cultural freedom to all other aspects of people's lives. The human development paradigm has the vantage point of widening people's choices and the enhancement of their lives (HDF, 2002). It is concerned with creating an environment in which people can develop their full potential and lead productive creative lives in line with their needs and interests. It considers people as the wealth of nations. It is about expanding the choices people have to lead lives that they value. This implies that human development is much more than economic growth. While economic growth is just one of the means of enlarging people's choices, there are other means

\footnotetext{
${ }_{1}$ See http://en.wikipedia.org/wiki/Human_development_(biology)

2 See http://en.wikipedia.org/wiki.Developmental_psychology

${ }^{3}$ See www.undp.org/rbec/nhdr/1996/georgia/glossary.htm

${ }^{4}$ See $h$ ttp://hdr.undp.org/hd
} 
of enlarging people's choices. Of fundamental importance in this regard is the building of human capabilities. By this is meant the range of things that people can do or be in life. The most basic capabilities for human development are to lead long and healthy lives, to be knowledgeable, to have access to the resources needed for a decent standard of living and to be able to participate in the life of the community. Without the above basic capabilities, many choices would be unavailable just as many opportunities would be inaccessible. Human well-being is thus the purpose and end of development.

Apart from the essential areas identified above or what we have referred to as the most basic capabilities, several other dimensions and aspects were later added and the concept was changed from "human development" to "sustainable human development". This was in order to emphasize the importance of sustaining all forms of capital and resources (including physical, human, financial and environmental resources) as a precondition for meeting the needs of future generations as well (Martinussen, 1996). Sustainable human development is thus conceptualized as:

\begin{abstract}
A paradigm of development that puts people, their ongoing needs and aspirations, at the centre of its concerns; that not only generates economic growth but distributes its benefits equitably, that regenerates the environment, that empowers people and that, because of their existing position of fewer opportunities, gives priority to the poor, enlarging their choices and opportunities and providing for their participation in decisions that affect their lives. ${ }^{5}$
\end{abstract}

The major difference between human development and sustainable human development is the fact that the latter pays attention to the factor of time. It is not just concerned with the present generation but also has the future generations in mind.

Human development shares a common vision with human rights. This common vision has freedom as its goal. In other words, in pursuing capabilities and realizing rights, human freedom is a sine qua non. People must be free to exercise their choices and to participate in decision-making that affects their lives. Thus, human development and human rights are mutually reinforcing. They both help to secure the well-being and dignity of all people, building self-respect and the respect of others. By well-being, is meant a "state of human existence in which a person's basic needs are adequately met and satisfied." ${ }^{\prime \prime}$ At the core of human development is people's well-being, for people are the real wealth of nations. The basic objective of development, therefore, is to create an enabling environment for people to live long, healthy and creative lives (UNDP, 1990). It is a process of enlarging people's choices. While the most critical choices are to lead a long and healthy life, to be educated and to enjoy a decent standard of living, additional choices include political freedom, guaranteed human rights and self respect (UNDP, 1990; Stewart, 2005).

What Mahbub ul Haq had in mind in creating the Human Development Report was "to shift the focus of development economics from national income accounting to people centered policies" (Haq, 1995). It was a broad ambition to set out a whole approach to development, with an agenda of policy priorities, tools of analysis and measurement, and a coherent conceptual framework. In the words of Jolly (2003), "Human Development approach embodies a robust paradigm, which may be contrasted with the neo-liberal paradigm of the Washington consensus. There are points of overlap, but also points of difference in objectives, assumptions, constraints and in the main areas for policy and in the indicators for assessing results."

\title{
4. Aspects of Human Development
}

From the definition(s) and explanation of the concept of human development, certain aspects of the paradigm emerge. These aspects were fairly agreed upon by the scholars who pioneered the paradigm. They include the following:

(i) The emphasis that development must put people at the centre of its concerns. It sees people as ends and not means.

(ii) That the purpose of development is the enlargement of human choices as opposed to the previous approaches which emphasized Gross National Product (GNP). In other words, the purpose of development goes beyond growth in income. It sees income as a means and not an end. Human development concerns widening of human choices; it gives priority to the freedom to choose.

(iii) The paradigm is concerned both with building up human capabilities (through investment in people and skill acquisition) and with using those human capabilities fully (through an enabling framework for growth and empowerment). Thus, while humans are seen as the objective of development, they are also an important resource in bringing about that development.

\footnotetext{
${ }^{5}$ See www.undp.org/rbec/nhdr/1996/georgia/glossary.htm

6 ibid.
} 
(iv) The human development paradigm defines the ends of development and analyses sensible options for achieving these ends (HDF, 2002).

While the human development paradigm, in practice, mainly focuses on basic needs including goods and services, it also discusses other issues such as freedom, democracy, gender, environment, communities and culture. It is thus open ended and all issues that may affect human beings' potential are brought in (Stewart, 2005).

The paradigm consistently maintains the view that economic growth is essential for human development. However, to maximally exploit the opportunities which that growth offers for improved well-being, that growth must be properly managed. The question then is: in what ways can the desirable links between economic growth and human development be created? There are four ways: (i) investment in education, health, and skills of people; (ii) more equitable distribution of income and assets; (iii) improvement in human development through well-structured social expenditures by the government; and (iv) empowerment of people, particularly women. These human development strategies approach every issue in the traditional growth model from the vantage point of people to establish the pre-eminence of people in the process of development. It is not to denigrate economic growth but to discover its real purpose (HDF, 2002).

The human development paradigm has certain characteristics which are worth noting. First, it has to be borne in mind that this paradigm is new and complex. It is not a finished theory but a paradigm still under construction. Second, the human development approach is multidimensional in the sense that it accomplishes different values. Mahbub ul Haq considers it as holistic while to Amartya Sen, it is pluralist. Again, the approach is critical in that it questions the prevailing neo-liberal theory. It is also inter-disciplinary, cutting across political philosophy, economics, statistics, social policy, sociology, political theory and other social sciences. Finally, the human development paradigm is pragmatic, having been born in the United Nations in dialogue with governments of member nations, it is aimed at changing human conditions.

Human development encompasses efficiency, equity, freedom and empowerment as well as sustainability. By efficiency is meant the efficient use of resources and increase of the availability of these resources. Thus, human development is pro-growth and productivity. By equity here, is meant distributive justice. This is especially for choices and opportunities. By freedom and empowerment is meant the possibility of choosing. This is vividly captured in Amartya Sen's assertion that freedom has a constitutive value (value by itself) and an instrument value (as a means to efficiency and equity). And, finally, sustainability implies that development in this context is not just for the present generation but also for future generations.

\section{Measuring Human Development}

In realization of the shortcomings of GNP as a measure of the level of development among nations, the need for an alternative measure of development became imperative. Following the adoption of human development as an alternative development paradigm, controversy arose with regard to the decision to attempt to measure it. The intrinsic problem with any measure basically revolved around which dimensions to include, the scale of measurement to use as well as how to weight the different elements to be included (Stewart, 2005).

In the early 1990s, the United Nations Development Programme (UNDP) developed what is now generally accepted as the most appropriate and effective yardstick for measuring human development. The index, called the Human Development Index (HDI), was actually developed in 1990 by the Pakistani economist, Mahbub ul Haq, and has been used since 1993 by the UNDP in its annual Human Development Report (UNDP, 2006b). The HDI is a comparative measure of life expectancy, literacy, education, and standards of living for countries on a global scale. It is a standard means of measuring well-being, especially child welfare, and by it countries are categorized as developed, developing or underdeveloped. It is also used to measure the impact of economic policies on quality of life (Davies \& Quinlivan, 2006). The HDI measures the average achievements in a country in three basic dimensions: (i) a long and healthy life, as measured by life expectancy at birth; (ii) knowledge, as measured by adult literacy rate (with two-thirds weight) and the combined primary, secondary, and tertiary gross enrolment ratio (with one-third weight); and (iii) a decent standard of living, as measured by gross domestic product (GDP) per capita at purchasing power parity (PPP) in US dollars. As UNDP (1994) succinctly puts it in the Human Development Report for that year, Human Development Index (HDI) is

a composite of three basic components of human development: longevity, knowledge and standard of living. Longevity is measured by life expectancy; knowledge is measured by a combination of adult literacy (two-third weight) and mean years of schooling (one third weight). Standard of living is measured by purchasing power, based on real GDP per capita adjusted for the local cost of living (purchasing power parity).

Countries are listed and ranked according to these measures on an annual basis. The value of the HDI ranges 
from 0 to 1, with higher values indicating greater levels of human development in the society (Elu, 2000). There are also the "disaggregated HDIs" for different regions or ethnic groups within a country. It should be noted, however, that the human development approach has often, unfortunately, been misconstrued as being narrowly limited to the three capabilities included in the HDI, or even more narrowly to their indicators (life expectancy, literacy and schooling, and adjusted income).

The HDI has been very useful and has played an important role in measuring the level of human development in different countries. However, Sen has argued that the idea of human development goes well beyond HDI (Stewart, 2005). New aspects of the human development paradigm are still being developed and modifications to the HDI have been suggested. These modifications include Gender-related Development Index (GDI) which measures average achievements of a country in basic human capabilities as the HDI does, but takes note of inequality in achievement between men and women; and a new measure of women's activity, the Gender Empowerment Measure (GEM) which examines whether women and men are able to actively participate in economic and political life and take part in decisionmaking. While GDI focuses on the enhancement of basic capabilities of women, GEM is concerned with the utilization of those capabilities to take advantage of the opportunities in life (UNDP, 1995). In 1996, a new multidimensional measure of human deprivation: the Capability Poverty Measure (CPM) was introduced. The measure is composed of three variables having equal weight in the index, expressed in percentage terms. The variables include: births unattended by trained health personnel, underweight children under five, and female illiteracy rate. A lower value of CPM is considered to be better (UNDP, 1996). After much elaboration and improvement, the CPM was, in the $1997 \mathrm{HDR}$, replaced by a new Human Poverty Index (HPI) (UNDP, 1997). Unlike CPM, HPI was intended to measure deprivation in terms of five, instead of three, variables: people expected to die before age 40; adults who are illiterate; people without access to health services; people without access to safe water; and underweight children under five. Again, a lower value of HPI indicates improvement against poverty (Jiyad, 1998). While the HDI measures national progress, the HPI measures the deprivations of those who are left out of the progress (UNDP, 1998; Tinker, 2001).

The HDI is an ingenious public-relations device, a ranking system that would directly rival the dominant indicator of GNP (Engler, 2005). Unlike the GNP, however, HDI is not blind to the social aspects of human lives. As such, countries like Norway, Canada, and Sweden, which, although not as wealthy as the United States, rank higher because they produce healthier citizens. Whereas the United States is accustomed to thinking of itself as number one in the world, the superpower, it regularly ranks between fourth and eighth on the HDI, trailing behind Norway, Canada and Sweden. As a matter of fact, the United States was eighth on the list of countries by HDI contained in the UNDP's 2006 Human Development Report, coming behind Norway, Iceland, Australia, Ireland, Sweden, Canada and Japan (UNDP, 2006a).

Few statistical tables make for as interesting reading as the HDI. It shows that Middle Eastern countries such as United Arab Emirates, Qatar, and Onan, whose investments in public education have been lacking, rank lower than they would if listed by GDP. Cuba ranks 39 places higher (Engler, 2005). The 2006 report shows that Vietnam (109) placed far better than Guinea (160), a country with similar per capita income, owing to much higher literacy rates and life expectancy.

The Human Development Index (HDI) facilitates an analysis of the state of Human Development-related affairs in a given country. However, it has been a subject of many criticisms and has drawn some controversies related to: limited dimension and variables, quality of data, the way in which income variable is treated, and suggestions to add political freedom, cultural values and environmental sustainability (Jiyad, 1998). The debates on HDI and the need for its improvement still continue. The new options of HDI created both at UNDP headquarters and in the countries indicate that there is room for rethinking the main approaches. However, it remains a far better yardstick for measuring the progress of nations than GNP.

\section{Capabilities and Freedom}

The terms "capabilities" and "freedom" are normally associated with Amartya Sen, the 1998 Nobel Prize winner for Economics. They are considered as part of his contributions to the founding of a new branch of human science of development. Sen's ideas of "functionings", and "capabilities" are significant in this regard. By "functionings", Sen (1987) means the various living conditions we can or cannot achieve, and by "capabilities" he means our ability to achieve these functionings. Sen's approach defined human development as the process of enlarging a person's "funtionings and capabilities to function, the range of things that a person could do and be in ... life" (Sen, 1989). This has been expressed in the Human Development Reports as expanding "choices". It is, however, not clear why the term "choices" replaced "capabilities" in the Human Development Reports. This replacement can actually cause confusion because the word "choice" is a common term that has different connotations to different persons. 
Some critics, Cohen (1993a; 1993b) for example, have argued that Sen has used, the word "capabilities" in at least two senses: one is that of actual attainment of various components of the standard of living, such as a certain level of income, state of health, education and so on, and the other is the potential of the persons concerned to attain these capabilities. However, since Sen connected his idea of capabilities and standard of living also with the actual freedom and rights enjoyed by people, we think that it adds to clarity of our understanding if we interpret "capabilities" as the potential attainable by people rather than their actual attainment of those standards. We may then, agree with Jiyad (1998) by considering capabilities as comprising of all aspects of human physical, intellectual and social endowments. To this we will also like to add spiritual endowments as well. This addition is necessitated by our conviction that the human is a three dimensional being composed of spirit, soul (or intellect, will, emotions) and body. Capabilities include a variety of needs the proper satisfaction of which is necessary to enhance a person's capacities and abilities such as good health, nutritious food, functional education, convenient housing, clean environment, safe neighbourhood, etc.

As Bagchi (1999) notes, Sen's formulation of the fullest attainment of human capabilities as the proper criterion of social welfare judgments and the appropriate objective of policy interventions connects with his idea of freedom. In Sen's view, freedom is not simply freedom to choose, but freedom from certain removable constraints on the functioning of human beings. Thus, in some way, Sen was able to resolve the conflict between the notion of positive and negative liberty. He also tried to remove the ambiguity surrounding the use of the concept of "capability" by providing a four-fold grid on which to put it. According to him:

\begin{abstract}
One distinction is between the promotion of a person's well-being, and pursuit of the person's overall agency goals. The latter encompasses the goals that a person has reasons to adopt, which can inter alia include goals other than the advancement of his or her well-being. The second distinction is between achievement, and the freedom to achieve. This contrast can be applied both to the perspective of well-being and to that of agency. The two distinctions together yield four different concepts of advantage, related to a person: (i) "well-being achievement", (ii) "agency achievement", (iii) "well-being freedom" and (iv) "agency freedom" (Sen, 1993 p. 35).
\end{abstract}

Sen was, therefore, able to relate his concepts of capability and freedom. Martha Nussbaum distinguishes between internal capabilities of a person and the external factors that facilitate such capabilities; and James Griffin's prudential values covers everything that makes a person's life better (Mozaffar, 1996 cited in Jiyad, 1998).

The Human Development Reports published annually since 1990 have used Amartya Sen's capability approach as a conceptual framework in their analyses of contemporary development challenges (Fukuda-Parr, 2003). Sen's idea of development is the expansion of capabilities. He sees the purpose of development as the improvement in human lives through expanding the range of things that a person can be and do, such as to be healthy and well nourished, to be knowledgeable, and to participate in community life. From this perspective, development is about removing the obstacles to what a person can do in life, obstacles such as illiteracy, ill health, lack of access to resources, or lack of civil and political freedoms (Fukuda-Parr, 2003).

Of the different capabilities, we see education or being knowledgeable as the bed rock; the foundation for all other capabilities. It is the principal effort that can be directed at the development and manifestation of the potentials and virtues that are inherent in the individual. Education should be such that enables the individual to discover and maximize his potentials. The development of potentials requires commitment and deliberate efforts at learning and applying knowledge gained. Education builds peoples capacity and enables them to acquire skills needed for the pursuit of developmental goals. It also equips them to have greater access to resources for enhanced standard of living and better quality of life. These together, will contribute to healthier living, reduced mortality and ultimately, higher life expectancy. It is through education and skill acquisition that opportunities become opened to individuals, their choices become enlarged and they also become empowered to participate in the development process and also to benefit from it.

\title{
7. Conclusion
}

The idea of development is a rather complex one. The concept had been poorly conceived and narrowly defined in terms of economic growth and increased income prior to the 1990s. But development has to be concerned with advancing human well-being and freedom. The concept of human development has therefore emerged as an alternative development paradigm which places emphasis on advancing the richness of human life rather than the richness of the economy. Viewed as the enlargement or enhancement of peoples' choices, it implies that it is a dynamic, evolutionary and continuous process. Choices connote freedom to choose or to take/make decisions that affect ones life as well as a freedom from certain removable constraints on the functioning of human beings such as fear, hunger, illiteracy, unemployment, exclusion, discrimination, persecution, etc. 
The Human Development Index (HDI), a composite of three components: longevity, knowledge and standard of living, is the tool now used to measure human development in nations. However, human development is not limited to these three basic capabilities included in the HDI. The interpretation of human development is very wide and it relates to all features of society that promote human flourishing, or prevent it. Although the new options of the HDI indicate that there is room for rethinking its main approaches, it is a better yardstick for measuring the progress of nations than GNP, a tool blind to the social aspects of human lives. Although UNDP began publishing the human development report since 1990, new aspects are still being developed. We consider investment in education the foundation for the building of all other capabilities.

\section{References}

Bagchi, A.K. (1999). Capabilities, freedom and human development: Amartya Sen's human science of development: Part III. Frontline, 16 (14) July, 03-16.

Cohen, G.A. (1993a). Amartya Sen's unequal world. Economic and Political Weekly, October, 2, 2156-60.

Cohen, G.A. (1993b). Equality of what? On welfare, goods, and capabilities. In M. Nussbaum, \& A.K. Sen (Eds.), The quality of life, Oxford: Clarendon Press.

Davies, A., \& Quinlivan, G. (2006). A panel data analysis of the impact of trade on human development. Journal of socioeconomics (http://www.business.duq.edu/faculty/davies/research/hdi.pdf)

Engler, M. (2005). From within the Labyrinth: A call for human development. New Internationalist, January.

Elu, J. (2000). Human development in sub-Saharan Africa: Analysis and prospects for the future. Journal of Third World Studies, Fall.

Fukuda-Parr, S. (2003). The human development paradigm: Operationazing Sen's ideas on capabilities. Feminist Economics 9 (2-3), $301-317$

Haq, Mahbub ul (1995). Reflections on Human Developm., New York: Oxford University Press.

Haque, M.S. (2004). The myths of economic growth (GNP): Implications for human development. In G. Madacumura \& M.S. Haque (Eds.), Handbook of Development Policy Studies (pp. 1-24). New York: Marcel Dekker.

Human Development Foundation (2002). Introduction to the human development concept. (http://www.yespakistan.com/ hdf/whywedoit/hdconcept.asp)

Jiyad, A.M. (1998). Human development paradigm under globalization environment. Paper presented at the Nordic conference on Middle Eastern Studies: The Middle East in globalizing world. Oslo, August 13-16.

Jolly, R. (2003). Human development and neo-liberalism: Paradigms compared. In S. Fukuda-Parr, \& A.K. Shiver Kumar (Eds.), Readings in Human Development: Concepts, Measures and Policies for a Development Paradigm. New Delhi: Oxford University Press.

Lerner, R.M. (1998). Handbook of Child Psychology. Vol. 1: Theoretical Models of Human Development. New York: Wiley.

Martinussen, J. (1996). Introduction to the concept of human development. (http://www.husdyr.kvl.dk/htm/php/tune96/1Martinussen.htm)

Obayan, A.O.I. (2005). Cultural intelligence and human development: The challenge of an emerging paradigm in a globalizing world. Paper presented at the International Conference on Human Development held at Covenant University, Ota, Nigeria. June 27-30.

Sen, A.K. (1987). The standard of living: Lecturer I, concepts and critiques. In A.K. Sen, R. Kambur, K. Hart, \& B. Williams (Eds.), The standard of living (the Tanner Lectures, 1985) (pp.1-19). Cambridge: Cambridge University Press.

Sen, A.K. (1988). The concept of development. In H. Chenery, \& T.N. Srinivasan (Eds.), Handbook of development economics. Amsterdam: North Holland.

Sen, A.K. (1989). Development as capabilities expansion. Journal of Development Planning 19, 41-58.

Sen, A.K. (1993). Capabilities and well-being. In M. Nussbaum, \& A.K. Sen (Eds.), The quality of life. Oxford: Clarendon Press.

Stewart, F. (2005). Human development as an alternative development paradigm. (www.undp.org/docs/training/oxford/presentation)

Streeten, P.P. (1994). Strategies for Human Development. Copenhagen: Munksgaard International Publishers.

Tinker, I. (2001). Poverty and gender in developing nations. In N.J. Smelser, \& P.B. Baltes (Eds.), International Encyclopedia of the Social and Behavioural Sciences. Vol. 17 p. 11901

UNDP (1990). Human Development Report 1990. New York: Oxford University Press.

UNDP (1994). Human Development Report 1994. New York: Oxford University Press.

UNDP (1996). Human Development Report 1996. New York: Oxford University Press.

UNDP (1997). Human Development Report 1997. New York: Oxford University Press.

UNDP (1998). Human Development Report 1999. New York: Oxford University Press.

UNDP (1999). Human Development Report 1999. New York: Oxford University Press.

UNDP (2000). Human Development Report 2000: Human Rights and Human Development. New York: Oxford University Press.

UNDP (2001a). Human Development Report 2001: Making New Technologies Work for Human Development. New York: Oxford University Press.

UNDP (2001b). The human development concept and paradigm change. National Human Development Report Armenia 2001 (http://www.undp.am/publications/nhdr01/main.php?1=en\&chapter=4id=4 4)

UNDP (2002). Human Development Report 2002: Deepening Democracy in a Fragmented World. New York: Oxford University Press.

UNDP (2006a). Human Development Report 2006: Power, Poverty and Global Water Crisis. New York: Oxford University Press.

UNDP (2006b). About HDRO (http://hdr.undp.org/aboutus?)

Williamson, J. (1990). What Washington means by policy reform. In J. Williamson (Ed.), Latin American adjustment: How much has happened? Washington, D.C.: Institute for International Economics.

World Bank (1980). World Bank Development Report 1980. Oxford University Press for the World Bank.

World Bank (1990). World Bank Development Report 1990, Oxford University Press for the World Bank. 